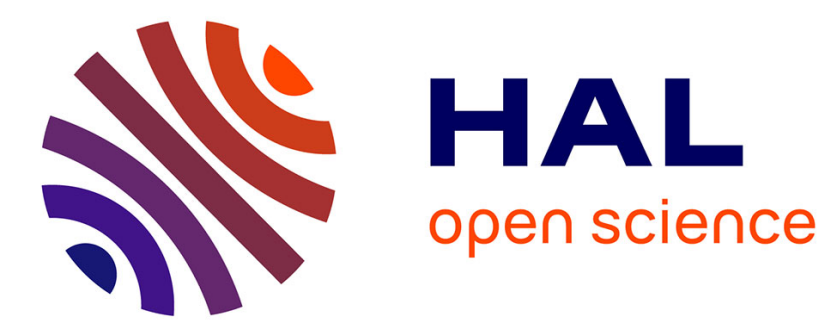

\title{
Effects of finishing processes on the fatigue life improvements of electro-machined surfaces of tool steel
}

Farhat Ghanem, Nabil Ben Fredj, Habib Sidhom, Chedly Braham

\section{To cite this version:}

Farhat Ghanem, Nabil Ben Fredj, Habib Sidhom, Chedly Braham. Effects of finishing processes on the fatigue life improvements of electro-machined surfaces of tool steel. International Journal of Advanced Manufacturing Technology, 2011, 52 (5-8), pp.583-595. 10.1007/s00170-010-2751-y . hal-02455204

\author{
HAL Id: hal-02455204 \\ https://hal.science/hal-02455204
}

Submitted on 25 Jan 2020

HAL is a multi-disciplinary open access archive for the deposit and dissemination of scientific research documents, whether they are published or not. The documents may come from teaching and research institutions in France or abroad, or from public or private research centers.
L'archive ouverte pluridisciplinaire HAL, est destinée au dépôt et à la diffusion de documents scientifiques de niveau recherche, publiés ou non, émanant des établissements d'enseignement et de recherche français ou étrangers, des laboratoires publics ou privés. 


\title{
Effects of finishing processes on the fatigue life improvements of electro-machined surfaces of tool steel
}

\author{
Farhat Ghanem • Nabil Ben Fredj • Habib Sidhom • \\ Chedly Braham
}

\begin{abstract}
Machining the EN X160CrMoV12 tool steel by electro-discharge machining (EDM) process generates significant modifications of microgeometrical, microstructural and mechanical properties of the upper layers of the machined components. In this paper, the role of these modifications in controlling the stability, under cyclic loading, of the propagation of the crack networks generated by EDM is discussed. High cycle fatigue tests $\left(2 \times 10^{6}\right.$ cycles) show that the presence of these cracks in brittle layers, i.e. white layer, quenched the martensitic layer, and a field of tensile residual stresses $(+750 \mathrm{MPa})$ results in a loss of $34 \%$ of endurance limit comparatively with the endurance evaluated for the milled state that generates crack-free surfaces. It is shown, in this work, that the detrimental effect of these crack networks can be controlled by putting in compression the upper layers of the EDM surfaces. Indeed the application of wire brushing to EDM surfaces generates compressive residual stresses $(\approx-100 \mathrm{MPa})$ that stabilise the crack networks propagation and therefore restores to the EDM surfaces their endurance limit value corresponding to the milled state. Moreover, removing the crack networks by polishing generates a stabilised residual stress value of $\approx-130 \mathrm{MPa}$. This results in an improvement rate of about $70 \%$ of the endurance limit comparatively with the EDM state and of $26 \%$ in
\end{abstract}

F. Ghanem $•$ N. B. Fredj $•$ H. Sidhom $(\bowtie)$

Laboratoire de Mécanique, Matériaux et Procédés, ESSTT,

5 Av. Taha Hussein, Montfleury,

1008 Tunis, Tunisia

e-mail: habib.sidhom@esstt.rnu.tn

C. Braham

LIM, CNRS UMR 8006, Arts et Métiers ParisTech (ENSAM), ENSAM

151 Boulevard de l'hôpital,

75013 Paris, France comparison to the milled state. These rates could be further increased by the application of the wire brushing process to the polished surfaces that reached $75 \%$ and $30 \%$ comparatively to the EDM and milling states respectively. In this case, a stabilised surface residual stress of about $\approx-150 \mathrm{MPa}$ was measured on the specimen surfaces.

Keywords EDM · Fatigue - Residual stress · Polishing · Wire brushing $\cdot$ Crack networks

\begin{tabular}{ll}
\multicolumn{2}{l}{ Nomenclature } \\
$A \%$ & Elongation \\
$\mathrm{EDM}$ & Electro-discharge machining \\
$K_{\mathrm{t}}$ & Stress concentration factor \\
$R_{\mathrm{t}}$ & Total roughness $(\mu \mathrm{m})$ \\
$N$ & Number of cycles \\
$R_{\mathrm{a}}$ & Average arithmetic roughness $(\mu \mathrm{m})$ \\
$R_{\mathrm{m}}$ & Rupture strength $(\mathrm{MPa})$ \\
$R_{\mathrm{p}(0.2)}$ & Yield strength $(\mathrm{MPa})$ \\
$R_{(\sigma)}$ & Loading ratio \\
$\sigma_{\mathrm{R}}$ & Residual stresses $(\mathrm{MPa})$ \\
$\sigma_{\mathrm{D}}$ & Endurance limit $(\mathrm{MPa})$ \\
$\sigma_{\max }$ & Maximum stress $(\mathrm{MPa})$ \\
$D$ & Isotropic damage variable
\end{tabular}

\section{Introduction}

Electro-discharge machining (EDM) is widely used for manufacturing of mechanical components with complicated shapes made on hard materials such as high- alloys, highspeed steels, and refract alloys [1]. It was reported that the high thermal effects generated during the material removal by this process induce mechanical, metallurgical and 
chemical modifications at the upper layers of the machined surfaces [2-9]. These layers are characterised by high work hardening, high tensile residual stresses and wide thermal crack networks that have detrimental effects on the fatigue life of EDM components [5, 8-11]. Previous studies have reported significant reductions of the endurance limit of EDM components comparatively with other machining processes.

Grosh [9] has indicated that EDM reduces the endurance limit of the EN X210Cr12A tool steel to $50 \%$ of its value evaluated when turning is used. Tadao et al. [10] have shown that EDM lowers by $60 \%$ the endurance limit of the cemented carbide D20 comparatively with polishing. When EDM was used instead of laser cutting, Kisuke et al. [11] have notified a reduction of $13 \%$ of the endurance limit when carbon steel $(0.45 \% \mathrm{C})$ was machined by these processes.

For these reasons, several investigations were conducted to improve the fatigue life of EDM components [11-19]. The main results of these works are summarised in Table 1. This table shows that three kinds of surface treatments have been extensively investigated: heat treatment, mechanical treatment and surface coating. According to this table, no general conclusion concerning the effects of heat treatment on the fatigue life of EDM surfaces can be given. It seems that the effect of this treatment is widely dependent on the work material type, EDM conditions and heat treatment parameters [11-13]. Concerning the mechanical and the coating treatments, Table 1 shows that an improvement rate ranging from $10 \%$ to $80 \%$ of the endurance limit can be realised by the application of these finishing techniques [14-16]. Moreover, this table shows that the most frequently used mechanical treatments for finishing the EDM surfaces are polishing and shot peening. The polishing uses abrasive paste that is capable of removing the damaged layer by EDM. AGIE [15] has shown that an increasing rate of $50 \%$ of the endurance limit can be realised by the application of polishing comparatively to the as-received state. This investigation showed also that this rate could be increased and reach a value of $80 \%$ by the application of shot peening to polished surfaces. Fordham et al. [14] indicated that an improvement rate of $33 \%$ of the endurance limit can be realised by the application of the shot peening process to the AISI 301 EDM surfaces. However, even though the application of these techniques improves significantly the fatigue life of mechanical components, they remain costly and technically complicated. Therefore, the development of much easier and more efficient finishing processes is more and more required.

One mechanical process that can introduce deliberately compressive residual stress into the upper layers of the machined surfaces by cold plastic deformation is wire brushing. This low-cost, fast and easy technique is commonly used for online debarring and removing of thin contaminated layers. Fredj et al. [20] have reported that this process can be used to improve the endurance limit of the AISI 304 stainless steel ground surfaces. An improvement rate of about $26 \%$ was reported in this investigation.

Based on these findings, and to continue investigating the improvements resulting from the application of mechanical treatments to EDM surfaces, experiments were conducted, in this study to evaluate and compare the fatigue life enhancements at $2 \times 10^{6}$ cycles of the EN $\mathrm{X} 160 \mathrm{CrMoV} 12$ tool steel EDM surfaces. In this investigation, wire brushing, polishing and polishing followed by wire brushing are considered. Mechanisms of fatigue crack initiation and propagation were investigated based on scanning electron microscopy (SEM) observations. It is important to notice that the mechanisms of fatigue crack initiation were investigated for the polished and wire brushed following polishing of EDM surfaces only. Indeed it is difficult to speak about any fatigue crack initiation for the EDM and for wire brushing after EDM because of the pre-existing damage, i.e. crack networks. In these cases, the roles of both damage and residual stresses on the fatigue behaviour of tested specimens are discussed.

\section{Material and experimental conditions}

\subsection{Material}

The tested material is the high alloy steel EN X160CrMoV12 for which the chemical composition (wt.\%) and mechanical properties are given in Table 2. The structure of the asreceived state is composed by ferritic matrix with dispersed chromium carbides (Fig. 1).

\subsection{Surface preparation modes}

Notched fatigue-flexion specimens with a stress concentration factor $K_{\mathrm{t}}=1.6$ are selected in this study (Fig. 2). The main advantage from using this geometry is the localised fatigue crack initiation and propagation at the notch root [20].

Notches were machined into the samples using a numerical control milling machine with an end mill having a diameter of $6 \mathrm{~mm}$. Only the notch was finished by the EDM process using a set of optimal finishing conditions that were determined in a previous work [8]. These conditions are listed in Table 3.

The experimental setups used for finishing the EDM surfaces by polishing and wire brushing can be described as follows:

- The wire brush was set on a conventional milling machine. During wire brushing, wires were effectively 


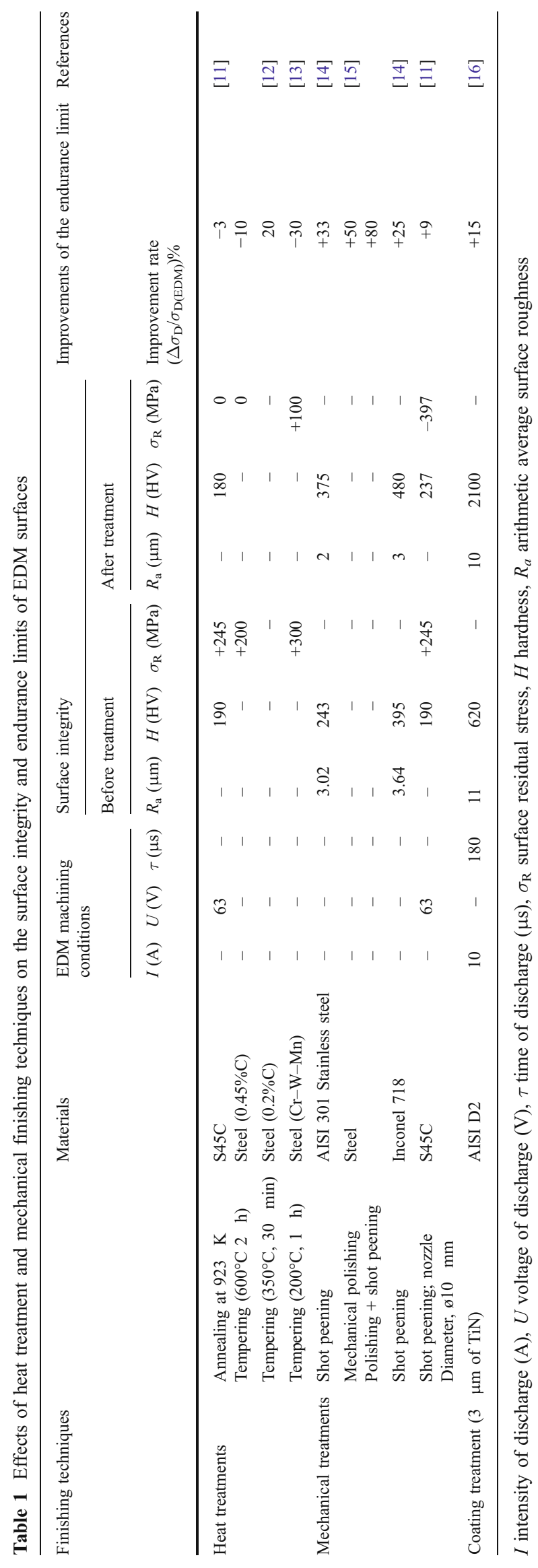

compressed by $3 \%$ of their length (the surface of the notch was set at $2.4 \mathrm{~mm}$ from the inner end of the wires) [20]. The experimental conditions selected for the wire brushing tests are listed in Table 4. These conditions were selected to generate high levels of compressive residual stresses without altering significantly either the workpiece dimensions or the brush wires.

- Concerning the polishing process, a special tool was used to polish the notch with diamond paste having an average diameter of $1 \mu \mathrm{m}$. The thickness of the removed layer by this finishing process was higher than $30 \mu \mathrm{m}$. This value corresponds to the thickness of the white layer initially generated by the EDM process [4].

\subsection{Surface characterisation}

Surface roughness was characterised using 2D, MITUTOYO SURFTEST 301, contact roughness measurement equipment. In this study, two roughness parameters were used: the average arithmetic roughness $R_{\mathrm{a}}$ and the total roughness $R_{\mathrm{t}}$. It was reported that these parameters can be used to characterise the local stress concentration zones at the root of the surface roughness. These zones properties affect significantly the fatigue behaviour of machined components $[21,22]$. The scan length used for the different roughness measurements was set to $8 \mathrm{~mm}$. Surface and in-depth residual stresses were evaluated using an SETX-type X-ray diffraction device. The parameters used for these measurements are given in Table 5. The near-surface hardness profiles were determined through Vickers micro-hardness measurements $\left(H \mathrm{v}_{100}\right)$ using a SHIMAZU HVM-2000 tester. Each measurement was repeated at last three times to increase the average value accuracy.

\subsection{Fatigue tests and surface damage analysis}

Three-point bending fatigue tests were conducted using an MTS 810 material testing machine with a frequency of $15 \mathrm{~Hz}$ and a loading ratio of $R_{(\sigma)}=0.1$. The fatigue behaviours of the notched specimens finished using the different finishing techniques were characterised by their endurance limit evaluated at $2 \times 10^{6}$ cycles using the staircase method [23]. The fatigue cracks nucleation and propagation mechanisms were investigated through SEM observations of fracture surfaces and fracture facieses. The in-depth crack networks propagation was evaluated through the measurement of their length at different cross-sections of the fatigue-tested specimens. 
Table 2 Chemical composition and mechanical properties of the EN X160CrMoV12 (as-received state)

\begin{tabular}{|c|c|c|c|c|c|c|c|c|c|c|c|c|c|}
\hline \multicolumn{10}{|c|}{ Chemical composition (wt.\%) } & \multicolumn{4}{|c|}{ Mechanical properties } \\
\hline $\mathrm{C}$ & $\mathrm{Si}$ & $\mathrm{Mn}$ & $\mathrm{P}$ & $\mathrm{S}$ & $\mathrm{Cr}$ & Mo & $\mathrm{N}$ & $\mathrm{V}$ & $\mathrm{W}$ & $\begin{array}{l}\text { Rupture strength, } \\
R_{\mathrm{m}}(\mathrm{MPa})\end{array}$ & $\begin{array}{l}\text { Yield strength, } \\
R_{\mathrm{p}(0.2)}(\mathrm{MPa})\end{array}$ & $\begin{array}{l}\text { Elongation, } \\
A(\%)\end{array}$ & Hardness (HB) \\
\hline 1.58 & 0.26 & 0.32 & 0.01 & 0.01 & 12.0 & 0.16 & 0.4 & 0.4 & 0.01 & 750 & 630 & 20 & 250 \\
\hline
\end{tabular}

\section{Results}

\subsection{Surface characterisation}

\subsubsection{Surface roughness}

Results of roughness measurements of surfaces generated using different finishing techniques show that:

- The lowest surface roughness is obtained by the polishing process $\left(R_{\mathrm{a}}=0.15 \mu \mathrm{m} ; R_{\mathrm{t}}=1.4 \mu \mathrm{m}\right)$.

- The roughness of the wire-brushed surfaces depends on the previously used machining process. Indeed it was found that, while the wire brushing process affects slightly the roughness of the EDM surfaces (wire brushing: $R_{\mathrm{a}}=$ $2.75 \mu \mathrm{m}, R_{\mathrm{t}}=17.9 \mu \mathrm{m}$; EDM: $\left.R_{\mathrm{a}}=2.40 \mu \mathrm{m}, R_{\mathrm{t}}=16.6 \mu \mathrm{m}\right)$, it generates higher roughness comparatively to polishing (wire brushing after polishing: $R_{\mathrm{a}}=0.70 \mu \mathrm{m}, R_{\mathrm{t}}=2.80 \mu \mathrm{m}$; polishing: $\left.R_{\mathrm{a}}=0.15 \mu \mathrm{m} ; R_{\mathrm{t}}=1.4 \mu \mathrm{m}\right)$.

\subsubsection{Surface defects}

- Near-surface defects

SEM observations of the EDM surfaces show a typical morphology consisting of superposed craters with high density of ramified micro-cracks (Fig. 3a). Concerning the surface morphology of the wirebrushed surfaces, the micrograph in Fig. $3 \mathrm{~b}$ shows material overlapping and re-deposition by the brush

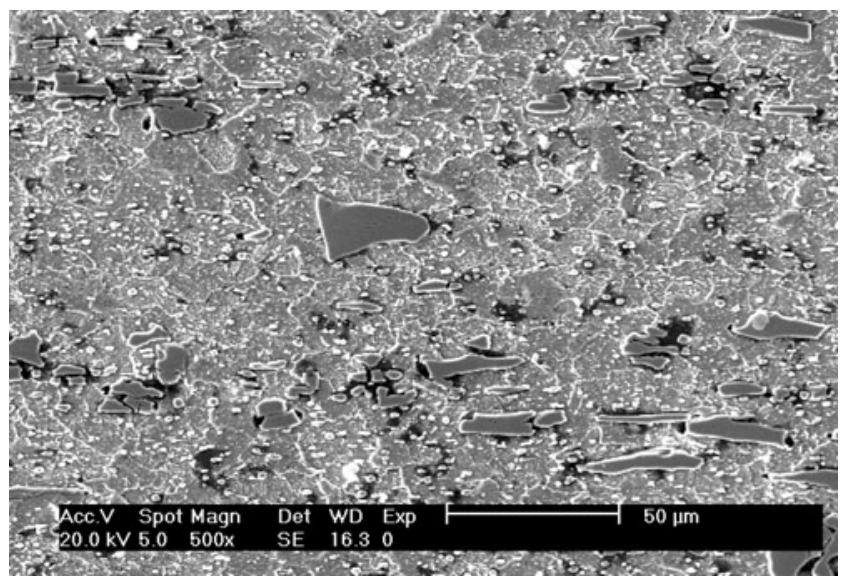

Fig. 1 Microstructure of EN X160CrMoV12 steel (as-received state) wires and micro-crack networks inside the craters. These suggest that not all the craters could be brushed as in many cases the brush wires could not penetrate inside to the crater. The flat topography of polished surfaces is characterised by grooves that are generated by the diamond abrasive grains (Fig. 3c). Concerning the wire-brushed and polished surfaces, ploughing traces generated by the successive passes of the brush wires were particularly observed. In this case, the grooves generated by the polishing process were completely removed by the brush wires (Fig. 3d).

- Surface under layers crack networks characterisation

Statistical analysis of the in-depth distribution of crack networks resulting from the different surface preparation modes was performed at different crosssections of the different specimens. Results show that almost $65 \%$ of cracks, generated by the EDM process, have lengths that are lower than $14 \mu \mathrm{m}$ (Fig. 4). A higher percentage was evaluated for the wire-brushed surfaces (83\%; Fig. 4). Meanwhile, the polished surfaces were totally exempt from the crack networks that are initially generated by the EDM process.

\subsubsection{Surface microstructure}

For EDM surfaces, the temperature gradient created by the electrical sparks generates a gradient of microstructure with a total thickness close to $120 \mu \mathrm{m}$. This microstructure gradient is characterised by three layers (Fig. 5). The thickness and hardness of these layers were evaluated at different positions and the following average values were calculated:

- The first layer is a brittle white layer that has a dendritic structure, an average thickness close to $\approx 40 \mu \mathrm{m}$ and a very high hardness $\left(H \mathrm{v}_{100 \mathrm{gf}}>800\right)$.



Fig. 2 Fatigue test specimen geometry (dimensions in millimetre) 
Table 3 Optimal machining conditions [8]

\begin{tabular}{ll}
\hline Intensity of discharge $(\mathrm{A})$ & 5 \\
Voltage of discharge $(\mathrm{V})$ & 46 \\
Time of discharge $(\mu \mathrm{s})$ & 5 \\
Polarity & Positive \\
Machining tool material & Graphite (Ellor7, intermediate grain size of $\approx 35 \mu \mathrm{m})$ \\
Dielectric liquid & Paraffin oil (dynamic viscosity $\mu=2.4 \times 10^{-3}$ Pa.s) \\
Feed of dielectric injection in interelectrode space $(1 / \mathrm{h})$ & 2
\end{tabular}

- The second layer is a martensitic quenched layer with an average thickness close to $\approx 50 \mu \mathrm{m}$ and a hardness $H \mathrm{v}_{100 \mathrm{gf}} \leq 800$.

- The third layer is a transition layer that is followed by the bulk material. This layer has an average thickness of about $\approx 30 \mu \mathrm{m}$.

This gradient of microstructure is not modified by the wire brushing. Meanwhile, the polishing process removes totally the white layer generated by the EDM process. Therefore, two competitive phenomena took place regarding to the surface hardness when wire brushing is applied consecutively to polishing:

- work softening resulting from the removal of the white layer by the polishing process

- work hardening resulting from the successive passes of the brush wires

For this finishing process, Fig. 6 shows a hardened layer that is softer and thicker (hardening rate $\approx 200 \%$, hardened layer thickness $\approx 200 \mu \mathrm{m}$ ) than the layer generated by EDM (hardening rate $\approx 300 \%$, hardened layer thickness $\approx 120 \mu \mathrm{m}$ ). When polishing and wire brushing were both applied to the EDM surfaces, the average values of the affected layer thickness and work hardening rate were around $160 \mu \mathrm{m}$ and $100 \%$, respectively. However, these values drop to $100 \mu \mathrm{m}$ for the affected layer thickness and to $60 \%$ for the work hardening rate when EDM surfaces were finished by the polishing process only. This is supposed to be the consequence of the removal of the hard white layer that was initially generated by the EDM process.

\subsubsection{Residual stresses distribution}

X-ray measurements of the residual stresses generated by the EDM process show an isotropic stress state (Table 6) with an average maximum value of $\sigma_{\mathrm{R}}=+750 \mathrm{MPa}$. This value was reached at the under layers (Fig. 7) because the near-surface crack networks relax these tensile residual stresses [4]. This state of residual stresses remains tensile at a depth up to $\approx 120 \mu \mathrm{m}$.

The surface finishing processes used in this study induce to the EDM surfaces compressive residual stresses. The highest values of these stresses are reached at the work surface (Fig. 7). The wire brushing process generates a surface compressive residual stress of about $-300 \mathrm{MPa}$. The polishing process was found to induce a compressive residual stress of about $-250 \mathrm{MPa}$ and this value was increased to $-330 \mathrm{MPa}$ when wire brushing was applied to the polished surfaces (Table 6). It is important to notice that the differences between these residual stresses are not very significant. In addition, these stresses are superficial as the thickness of the compressed layers ranges from 30 to $80 \mu \mathrm{m}$ only for the different surface finishing modes (Fig. 7).

\subsection{Fatigue resistance}

\subsubsection{Effects of the finishing processes on the fatigue behaviour}

The S-N curves, given by Fig. 8, show the beneficial effects of the finishing processes used in this study on the fatigue strength of EN X160CrMoV12 compared to EDM. As it is summarised in Table 7 , the endurance limit $\sigma_{\mathrm{D}}$ at

Table 4 Selected conditions for wire brushing tests [20]

\begin{tabular}{|c|c|c|c|c|c|c|}
\hline $\begin{array}{l}\text { Diameter of the brush } \\
(\mathrm{mm})\end{array}$ & $\begin{array}{l}\text { Diameter of wire } \\
(\mathrm{mm})\end{array}$ & $\begin{array}{l}\text { Length of wire } \\
(\mathrm{mm})\end{array}$ & $\begin{array}{l}\text { Speed of the brush } \\
(\mathrm{rpm})\end{array}$ & $\begin{array}{l}\text { Feed }(\mathrm{mm} / \\
\min )\end{array}$ & $\begin{array}{l}\text { Number of } \\
\text { passes }\end{array}$ & $\begin{array}{l}\text { Compression } \\
\text { percentage }^{\mathrm{a}}\end{array}$ \\
\hline$D=230$ & $\phi=0.1$ & $L=80$ & $V_{\mathrm{s}}=2000$ & $V_{\mathrm{f}}=50$ & 10 & $3 \%$ \\
\hline
\end{tabular}

${ }^{a}$ Engaged length/wire length (engaged length of the wire $=2.4 \mathrm{~mm}$ ) 
Table 5 X-ray diffraction conditions

\begin{tabular}{ll}
\hline Target & $\mathrm{Cr}$ \\
Wave length $K_{\alpha} 1(\AA)$ & 2.2897 \\
Filter & $\mathrm{V}$ \\
Diffraction plane hkl & 211 \\
Bragg angle $\left({ }^{\circ}\right)$ & 156.3 \\
Current & $5 \mathrm{~mA}$ \\
Voltage & $20 \mathrm{kV}$ \\
Goniometer tilt & $\mathrm{Psi}$ \\
Beam section & $\varnothing=1.5 \mathrm{~mm}$ \\
Young's modulus $(E)$ for steel & $210 \mathrm{GPa}$ \\
Poisson ratio $(v)$ & 0.33 \\
Number of Psi angles & $13\left(\right.$ from $-36.3^{\circ}$ to $\left.+39.2^{\circ}\right)$ \\
Number of Phi angles & $2\left(0^{\circ}\right.$ and $\left.90^{\circ}\right)$ \\
\hline
\end{tabular}

$2 \times 10^{6}$ cycles of the EDM specimens could be significantly increased by the application of the different surface finishing modes. The improvement rates of the endurance limit realised by the application of the wire brushing process, polishing and both polishing followed by wire

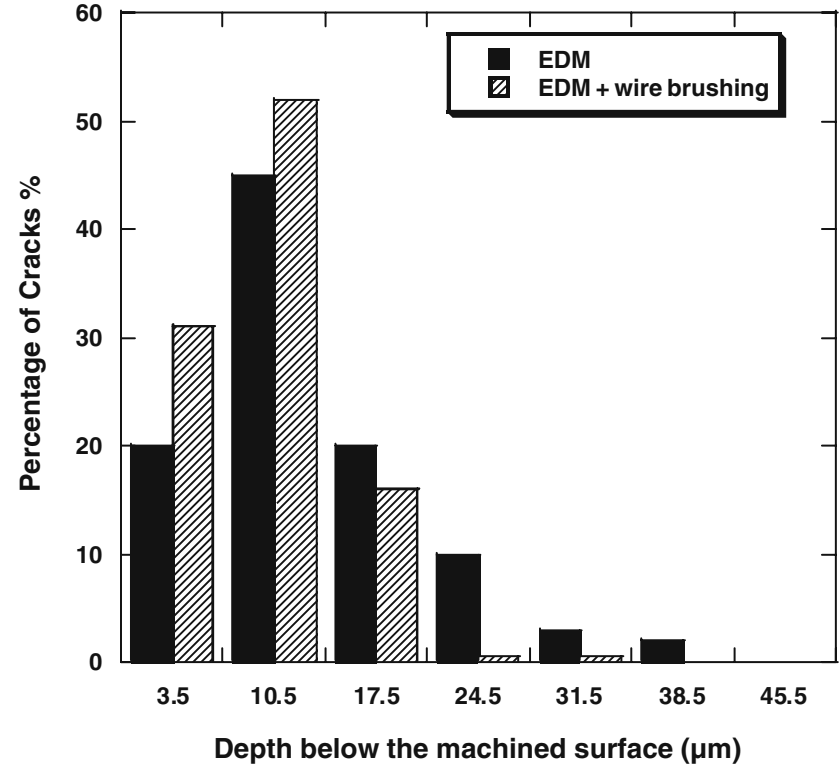

Fig. 4 Distribution of crack depths for the EDM and wire-brushed specimens before cyclic loading
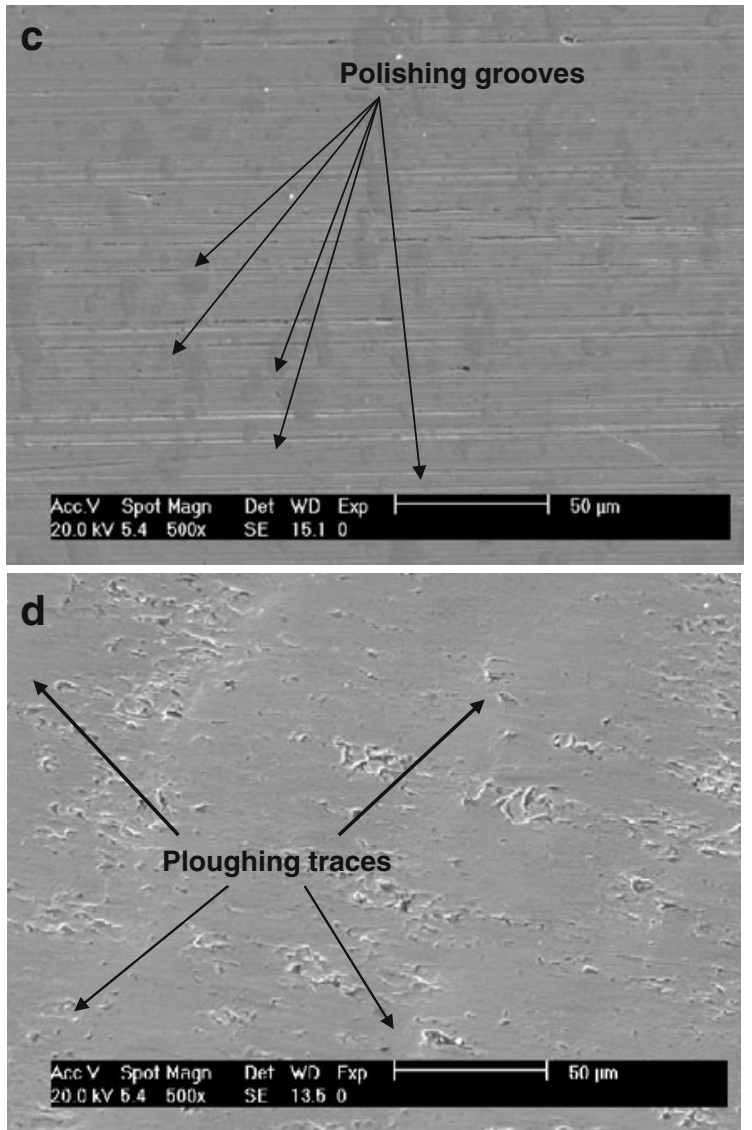

Fig. 3 Micrographs of surfaces finished using different techniques. a General aspects of electro-discharge machined surface. b General aspects of wire-brushed surface. $\mathbf{c}$ General aspects of polished surface. d General aspects of polished and wire-brushed surface 


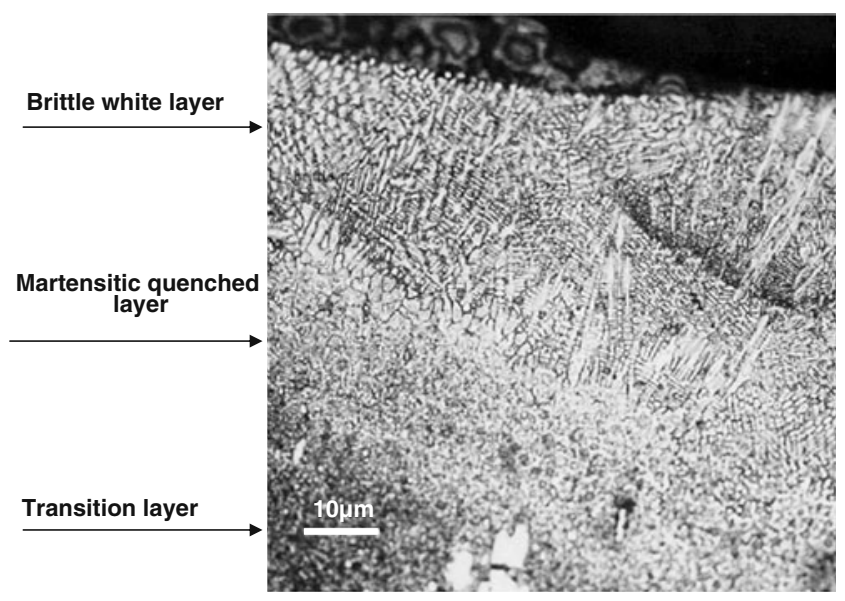

Fig. 5 Metallurgical transformations of EDM surface

brushing comparatively to EDM are $34 \%, 70 \%$ and $75 \%$, respectively. These values are $0 \%, 26 \%$ and $30 \%$ comparatively with the milled state that generates crackfree surfaces. The endurance limit corresponding to the milled state was evaluated at $\sigma_{\mathrm{D}}=250 \mathrm{MPa}$ in previous work [5].

\subsubsection{Roles of the crack networks created by the EDM process}

SEM examinations of the fatigue-tested specimens fracture surface, finished by the different techniques, used in this study put in evidence:

- The role of the crack networks generated by the EDM process in controlling the main fatigue crack leading to

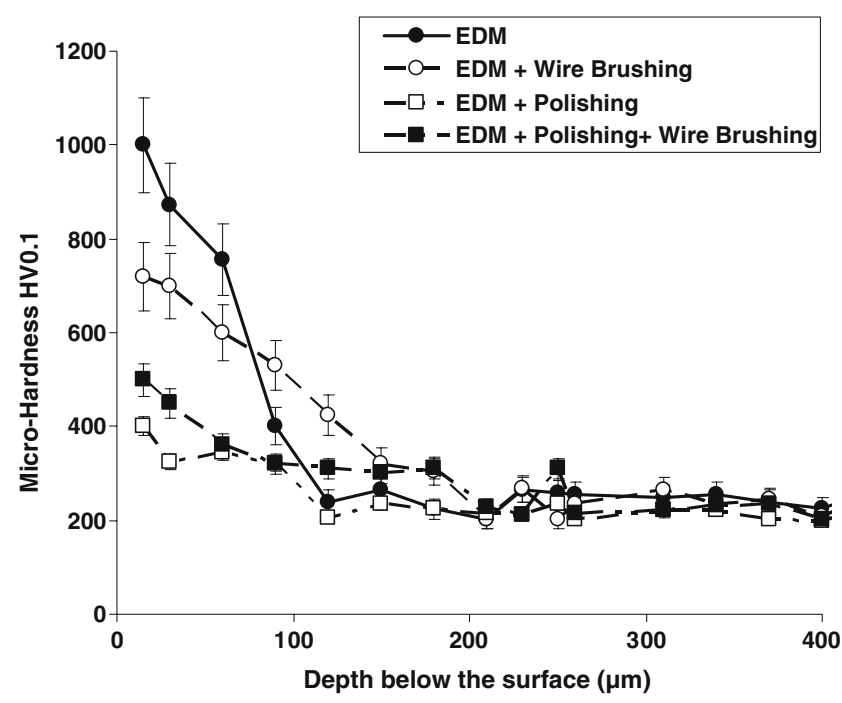

Fig. 6 Micro-hardness profiles of different specimens finished using EDM, EDM and wire brushing, EDM and polishing, EDM and both polishing and wire brushing

the work rupture- - this crack is the ramification of crack networks generated by the EDM process (Fig. 9a).

- a similar role is observed in the case of wire-brushed specimens even though the crack networks, previously generated by the EDM process, are slightly removed by the successive passes of the brush wires (Fig. 9b).

- The role of the polishing grooves in controlling the fatigue fracture of polished specimens-It is important to notice that, in this case, the crack networks generated by the EDM process are completely removed by the abrasive paste (Fig. 9c).

- A similar role to the polishing grooves combined with the effects of the material re-deposition and overlapping

Table 6 Comparison of surface residual stresses before and after cyclic loading

\begin{tabular}{|c|c|c|c|c|}
\hline \multirow{2}{*}{ Surface preparation mode } & \multicolumn{2}{|c|}{ Before cyclic loading } & \multicolumn{2}{|c|}{ After $2 \times 10^{6}$ cyclic loading } \\
\hline & $\sigma_{\mathrm{xx}}(\mathrm{MPa})$ & $\sigma_{\mathrm{yy}}(\mathrm{MPa})$ & $\sigma_{\mathrm{xx}}(\mathrm{MPa})$ & $\sigma_{\mathrm{yy}}(\mathrm{MPa})$ \\
\hline EDM & $+400 \pm 50$ & $+400 \pm 50$ & $135 \pm 15$ & $90 \pm 15$ \\
\hline EDM + Wire Brushing & $-300 \pm 50$ & $-220 \pm 50$ & $-120 \pm 25$ & $-100 \pm 25$ \\
\hline EDM + Polishing & $-250 \pm 20$ & $-240 \pm 20$ & $-213 \pm 20$ & $-130 \pm 20$ \\
\hline $\begin{array}{l}\text { EDM + Polishing + Wire } \\
\text { Brushing }\end{array}$ & $-330 \pm 30$ & $-230 \pm 30$ & $3 \pm 25$ & $-150 \pm 25$ \\
\hline \multicolumn{2}{|c|}{$\begin{array}{c}\sigma_{x X} ; \text { Residual stresses measured according to } \\
\text { XX direction } \\
\sigma_{y y}: \text { Residual stresses measured according to } \\
\text { YY direction }\end{array}$} & & & \\
\hline
\end{tabular}




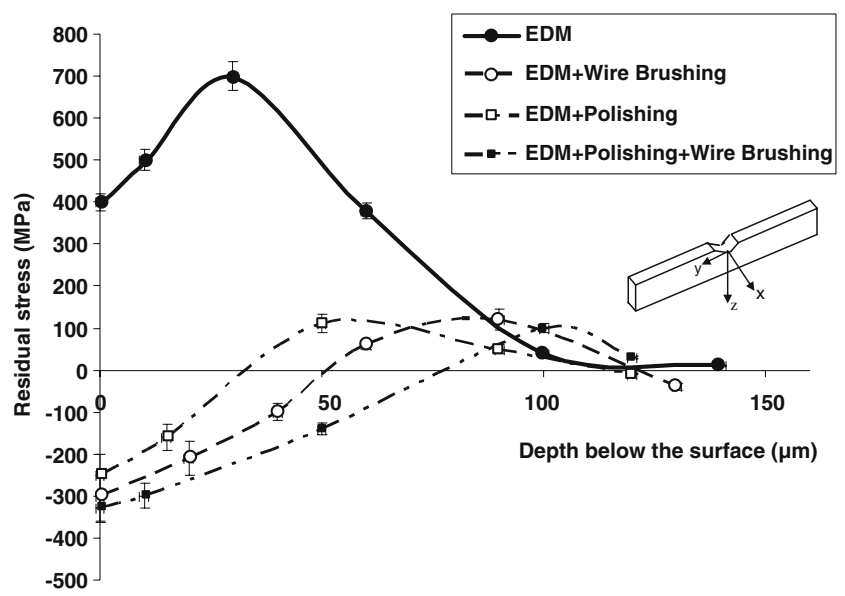

Fig. 7 Residual stresses profiles measured according to the $(X X)$ direction

is observed for the wire-brushed specimens that were previously polished (Fig. 9d).

\subsubsection{Role of the surface microstructure}

Examinations of the facieses of the fatigue-fractured specimens show brittle first-stage fatigue crack propagation at the hardened layers that are:

- white layer for the EDM and wire-brushed specimens (Fig. 10a, b)

- quenched layer for the polished and polished and wirebrushed surface (Fig. 10c, d)
Table 7 Endurance limit and improvement rates

\begin{tabular}{lll}
\hline $\begin{array}{l}\text { Surface preparation } \\
\text { mode }\end{array}$ & $\begin{array}{l}\text { Endurance limit } \\
\sigma_{\mathrm{D}}(\mathrm{MPa})\end{array}$ & $\begin{array}{l}\text { Improvement rate } \\
\left(\Delta \sigma_{\mathrm{D}} / \sigma_{\mathrm{D}(\mathrm{EDM})}\right), \%\end{array}$ \\
\hline $\mathrm{EDM}$ & $185 \pm 20$ & - \\
$\mathrm{EDM}+$ wire brushing & $247 \pm 17$ & +34 \\
$\mathrm{EDM}+$ polishing & $315 \pm 10$ & +70 \\
$\mathrm{EDM}+$ polishing + & $325 \pm 10$ & +75 \\
wire brushing & & \\
\hline
\end{tabular}

- cupules observed at the ferritic matrix of the fracture facieses bulk indicate that the fatigue crack propagation is ductile in the bulk material

\subsubsection{Role of the residual stresses}

Residual stress profiles measured at the notch root of nonfractured fatigue-tested specimens (at $2 \times 10^{6}$ cycles) and loaded at a stress level close to the endurance limit reveal the following:

- A partial cyclic relaxation of the tensile residual stresses measured at the main loading direction for EDM surfaces (Fig. 11a). Therefore, the crack networks generated by the EDM process remain in a tensile residual stress field, yielding to a stress instability state that accelerates the crack networks propagation.

- A partial cyclic relaxation of the compressive residual stresses at the main loading direction of the brushed specimens (Fig. 11b). Therefore, the crack networks
Fig. 8 WöHLER curves for various surface preparations

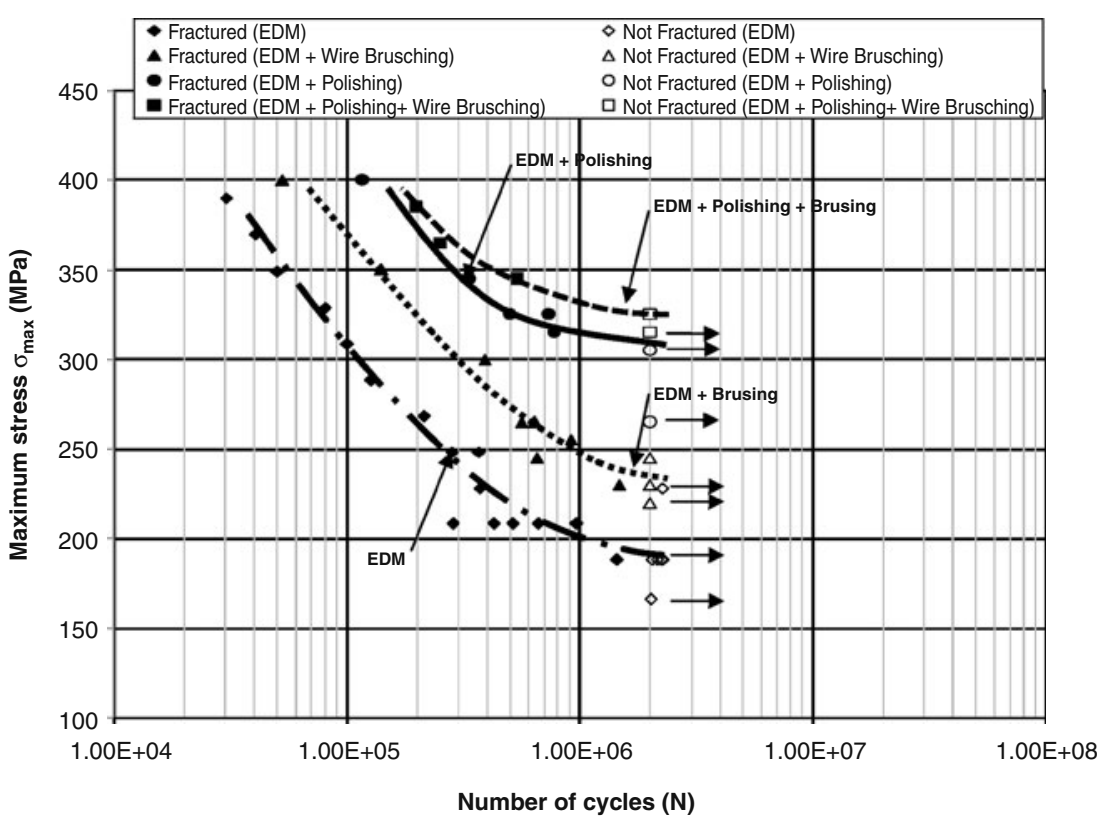



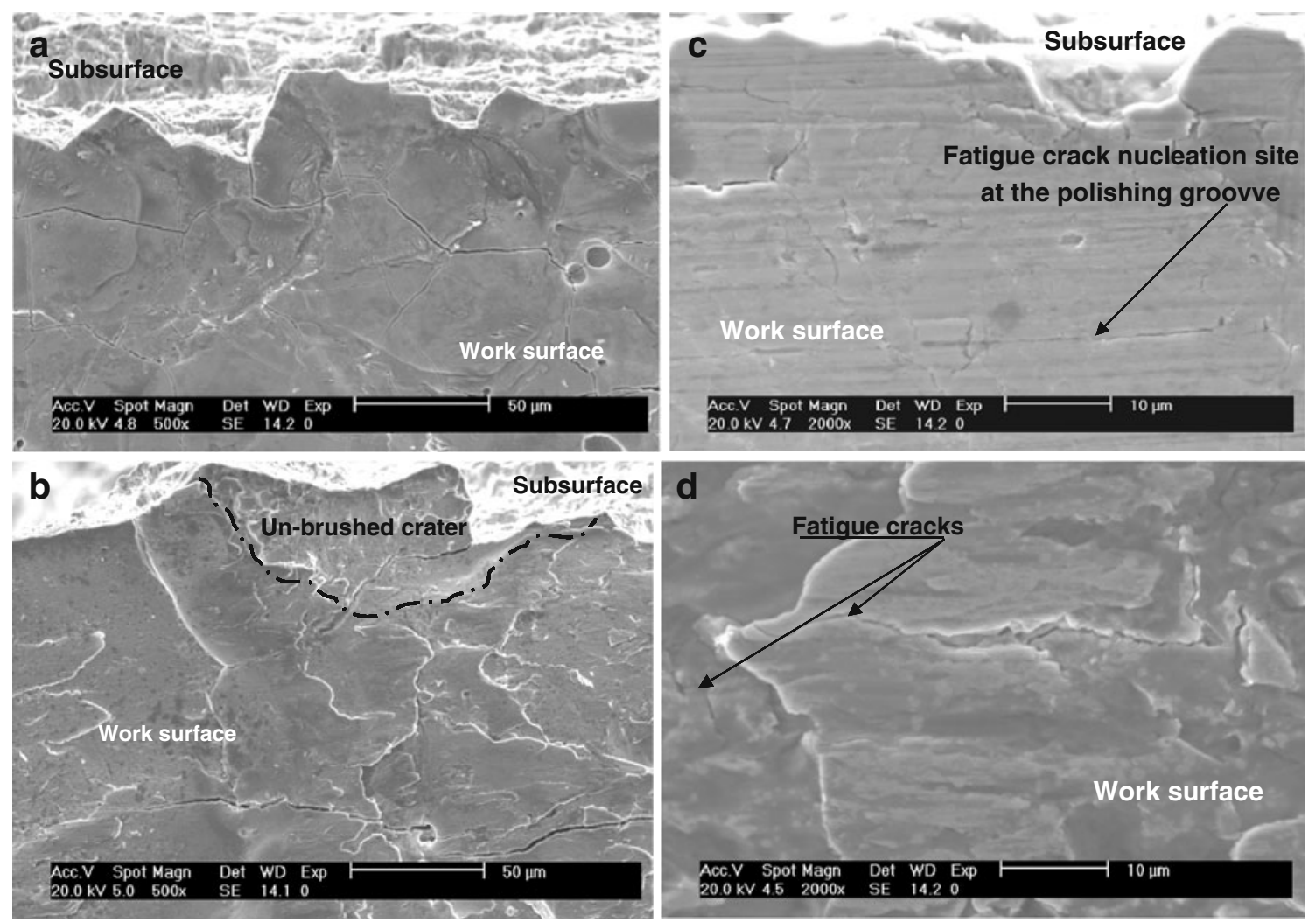

Fig. 9 Fatigue fracture surface micrographs: cracks generated by EDM propagating by cyclic loading for EDM and wire-brushed specimens (a, b); fatigue cracks nucleation and propagation by cyclic loading for polished and wire-brushed-after-polishing surfaces $(\mathbf{c}, \mathbf{d})$. a Crack networks ramifying by cyclic loading at the notch root for $\operatorname{EDM}\left(\sigma_{\max }=190 \mathrm{MPa} ; R=0.1 ; N=1968138\right.$ cycles $)$. b Crack networks

initially generated by the EDM process remain in a compressive residual stress field. This stabilises the stress state regarding to the fatigue crack propagation.

- Similar residual stress relaxation effects to the wirebrushed surfaces occur for polished and both polished and wire-brushed surfaces. Indeed the compressive residual stress states generated by the polishing and wire brushing consecutive to polishing remain compressive even after fatigue loading at $2 \times 10^{6}$ cycles (Table 6).

Comparison of the quantitative evaluation of cracks depth density before and after cyclic loading of EDM specimens under at a stress level close to the endurance limit puts in evidence the high instability of the crack networks. The evaluation was made through SEM observations of crosssections of unloaded and cyclically loaded specimens under a stress level close to the endurance limit (non-fractured). Histograms given by Fig. 12 show that almost $30 \%$ of cracks that were initially generated by the EDM process have reached a depth ranging from 30 to $50 \mu \mathrm{m}$ (initial depth around $14 \mu \mathrm{m}$ ) after $2 \times 10^{6}$ cyclic loading (Fig. 12a).

ramifying by cyclic loading at the notch root for wire brushing $\left(\sigma_{\max }=\right.$ $255 \mathrm{MPa} ; R=0.1 ; N=1911333)$. c Crack ramifying by cyclic loading at the notch root for polished surfaces $\left(\sigma_{\max }=325 \mathrm{MPa} ; R=0.1 ; N=\right.$ 1733435 cycles). d Crack propagation by cyclic loading for wirebrushed-after-polishing surfaces $\left(\sigma_{\max }=345 \mathrm{MPa} ; R=0.1 ; N=1540404\right.$ cycles)

Concerning the wire-brushed surfaces, cracks inside the craters that were not reached by the wires of the brush propagate and ramify to form continuous fatigue crack networks, leading to the failure of the wire-brushed specimens. These crack networks seem to be stopped in depth by the compressive residual stresses as similar crack networks depth density were obtained before and after cyclic loading (Fig. 12b). Therefore, it can be stated that the propagation of the crack networks generated by the EDM process could be stabilised and their detrimental effects regarding to the fatigue crack propagation could be controlled by the different finishing techniques used in this work.

\section{Discussion}

In this work, the effects of different mechanical treatments on the EDM surface integrity are investigated and their consequences on the fatigue behaviour improvements are assessed. These treatments include polishing, wire brushing and the combination of polishing and wire brushing processes. 

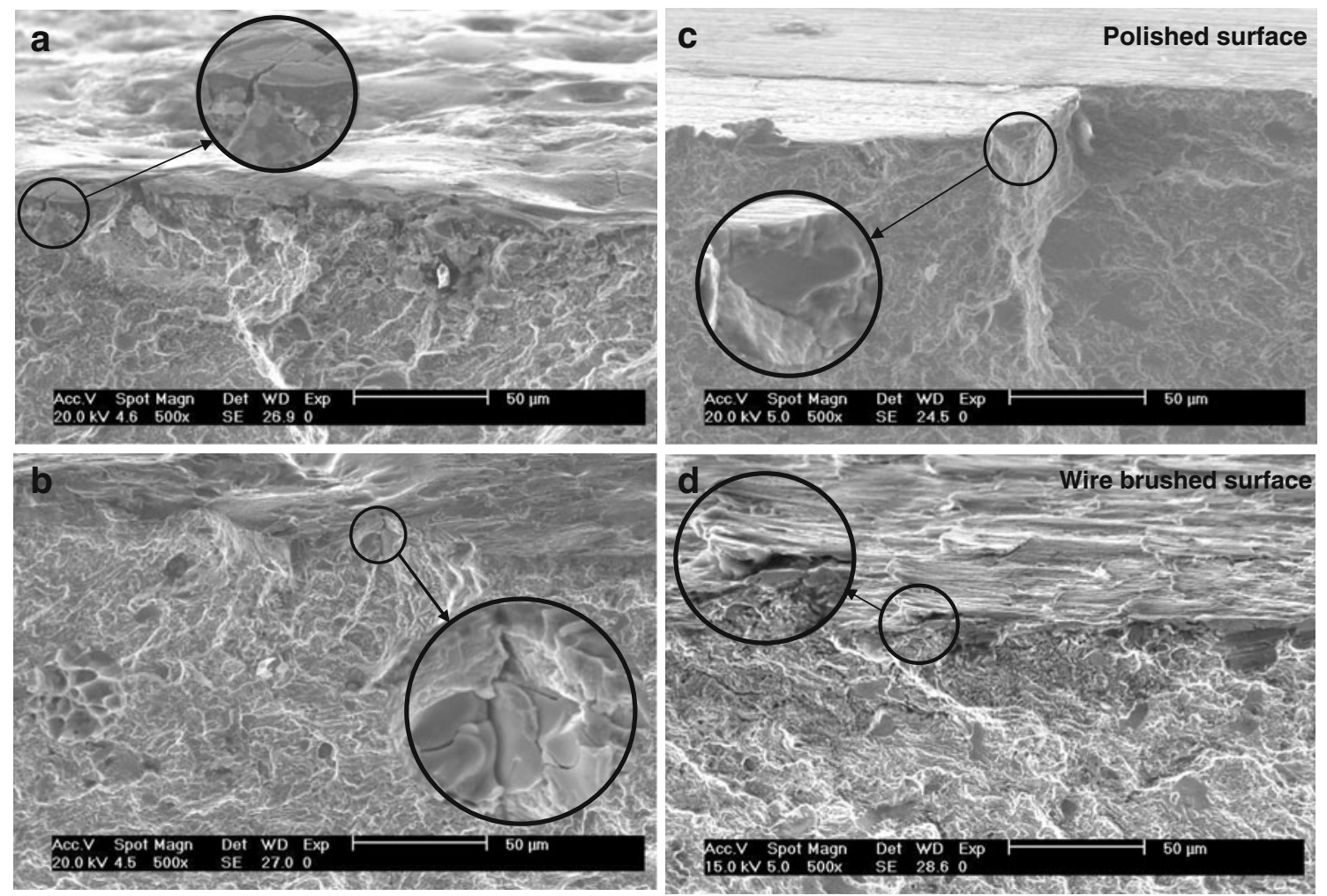

Fig. 10 Fatigue facieses micrographs: cracks generated by EDM propagating by cyclic loading for EDM and wire-brushed specimens (a, b); fatigue cracks nucleation and propagation by cyclic loading for polished and wire-brushed-after-polishing surfaces (c, d). a Cracks generated by EDM propagating by cyclic loading (EDM specimens, $\sigma_{\max }=190 \mathrm{MPa} ; R=0.1 ; N=1968138$ cycles $)$. b Cracks generated by

EDM and propagating by cyclic loading (wire-brushed specimens after EDM $\sigma_{\max }=255 \mathrm{MPa} ; R=0.1 ; N=1911333$ ). c Fatigue cracks nucleation and propagation at the polishing grooves $\left(\sigma_{\max }=325 \mathrm{MPa}\right.$; $R=0.1 ; N=1733435$ cycles). d Fatigue cracks nucleation and propagation for polished and wire-brushed surfaces $\left(\sigma_{\max }=345 \mathrm{MPa}\right.$; $R=0.1 ; N=1540404$ cycles)

\subsection{Surface integrity improvements}

The surface integrity improvements realised by the application of the different surface finishing techniques can be summarised as follows:

\section{- Surface roughness}

It was observed that while polishing removes the defects generated by the EDM process and improves the surface roughness, the wire brushing was unable to completely eliminate these defects. Within the experimental conditions used in this investigation, the thickness of the removed layer by the wire brushing was much smaller than the thickness of the hard white layer initially generated by the EDM process. As this white layer controls the surface topography of the EDM surfaces [24], no significant improvements of the roughness state could be realised by the application of the wire brushing. However, the diamond abrasive grains used by the polishing process could easily

remove this white layer and generate a new surface topography characterised by the lowest roughness level comparatively with the other surface preparation modes.

- Brittle layers

It was previously stated that the microstructural modifications induced by the EDM process yield to the formation of hard and brittle layers that have detrimental effects on the fatigue resistance of components machined by this process [4-9].

In this study, it is shown that the successive passes of the brush wires generate on a slight material removal of the upper layers of the EDM surfaces and on an additional cold work hardening to these surfaces. The former phenomenon induces a reduction of the initial surface hardness, while the latter increases the thickness of the hardened layers. Concerning the polished surfaces, as mentioned above, the successive passes of the abrasive grains remove totally the white layer initially generated by the EDM process. As a result, significant reductions of both surface hardness and hardened layer 


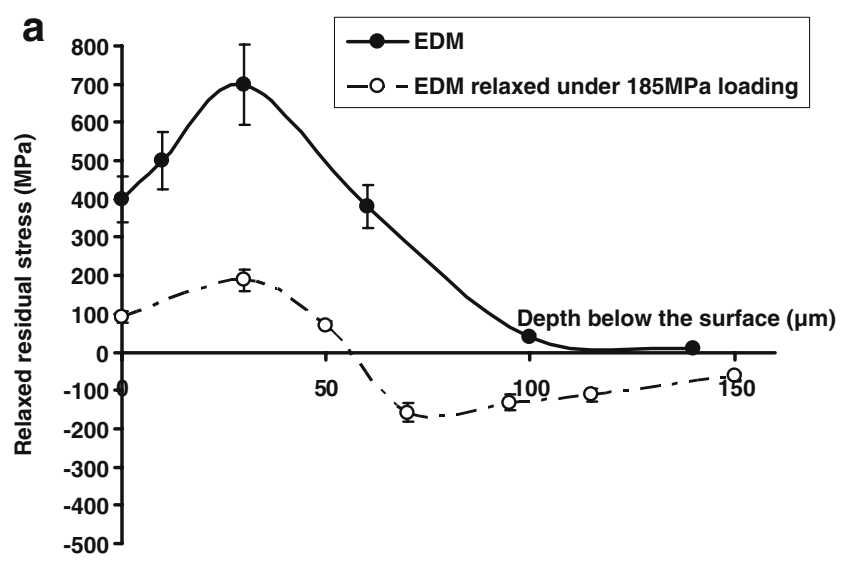

The existence of these crack networks in a field of tensile residual stresses is the main reason of their instability regarding to the coalescence and propagation of these cracks under cyclic loading. The application of the wire brushing process puts in compression the surface upper layers and therefore stabilises the crack networks propagation. Concerning the polishing process, this finishing technique was found to eliminate completely the crack networks, so that crack free surfaces could be generated.

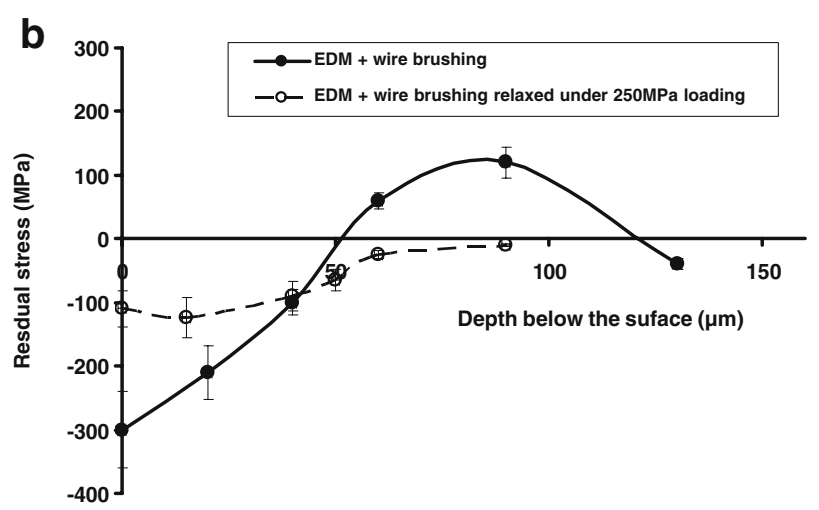

Fig. 11 Relaxed residual stress profiles for EDM and wire-brushed surfaces after EDM. a Relaxed residual stress profiles for EDM specimens. b Relaxed residual stress profiles for wire-brushed-afterEDM specimens

thickness occur. The application of the wire brushing to the polished surfaces induces an additional hardening by plastic deformations of the upper layers.

- Residual stress distributions

The high levels of the tensile residual stresses measured at the EDM surfaces are generated by the high thermal effects and metallurgical transformations that are specific to the material removal mechanism by this process $[8,9,13,14]$. The mechanical effects generated by the wire brushing process generate compressive residual stresses at the upper layers of the EDM surfaces. These levels are comparable to those obtained by shot-peeing when this process is applied to finish steel surfaces initially machined by EDM [10, 14, 15]. The polishing process was found to generate similar effects. The level of the compressive residual stresses could be increased by the application of wire brushing to polished surfaces.

- Control and stabilisation of EDM crack networks

The crack networks observed at the EDM surfaces are generated by the high levels of the thermal stresses.
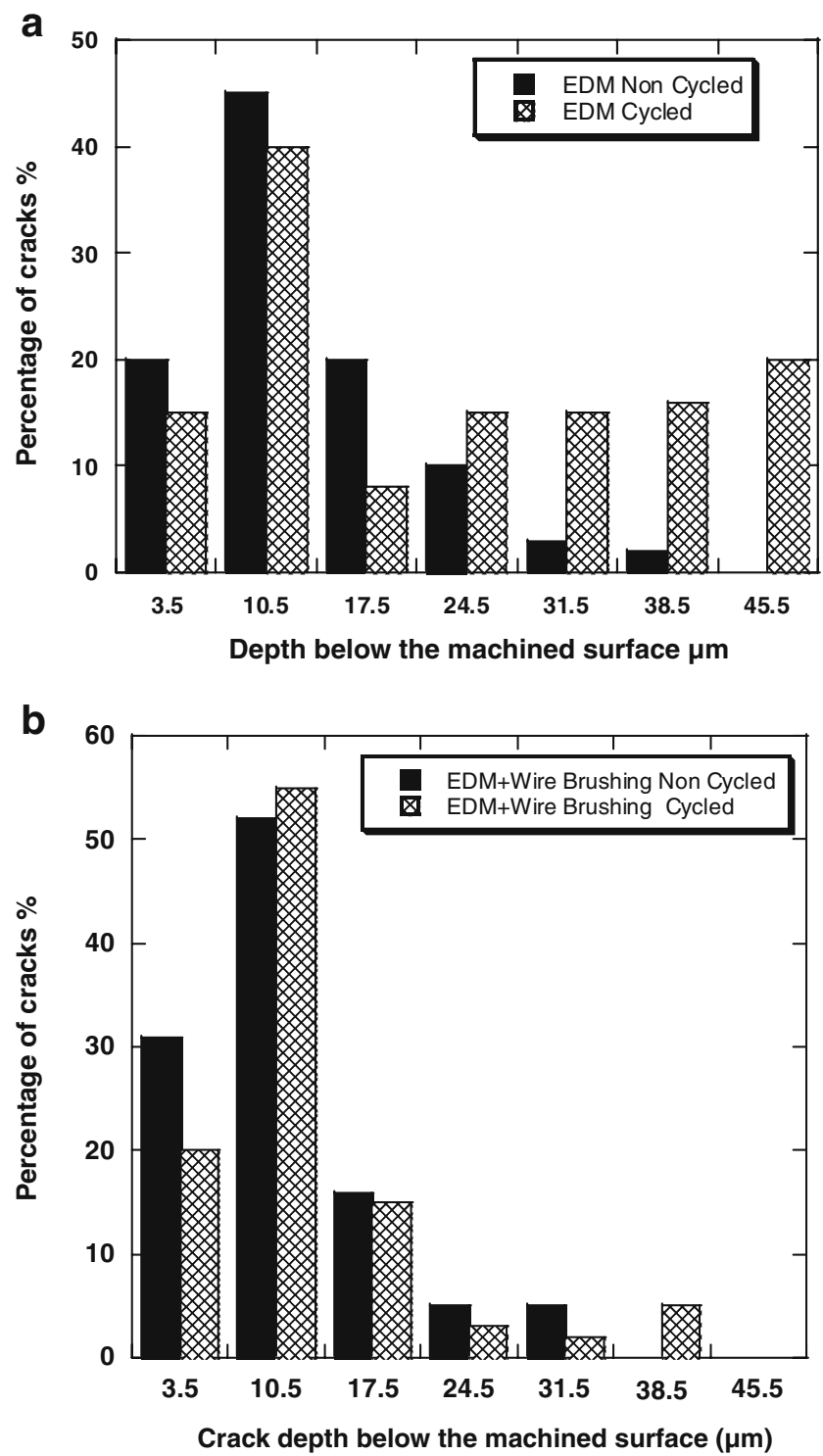

Fig. 12 Distribution of in-depth micro-cracks before and after cyclic loading at $2 \times 10^{6}$ cycles. a Crack depth densities for electro-machined surface. b Crack depth densities for wire-brushed surface after electromachining 
Fig. 13 Diagram of GoodmanSmith

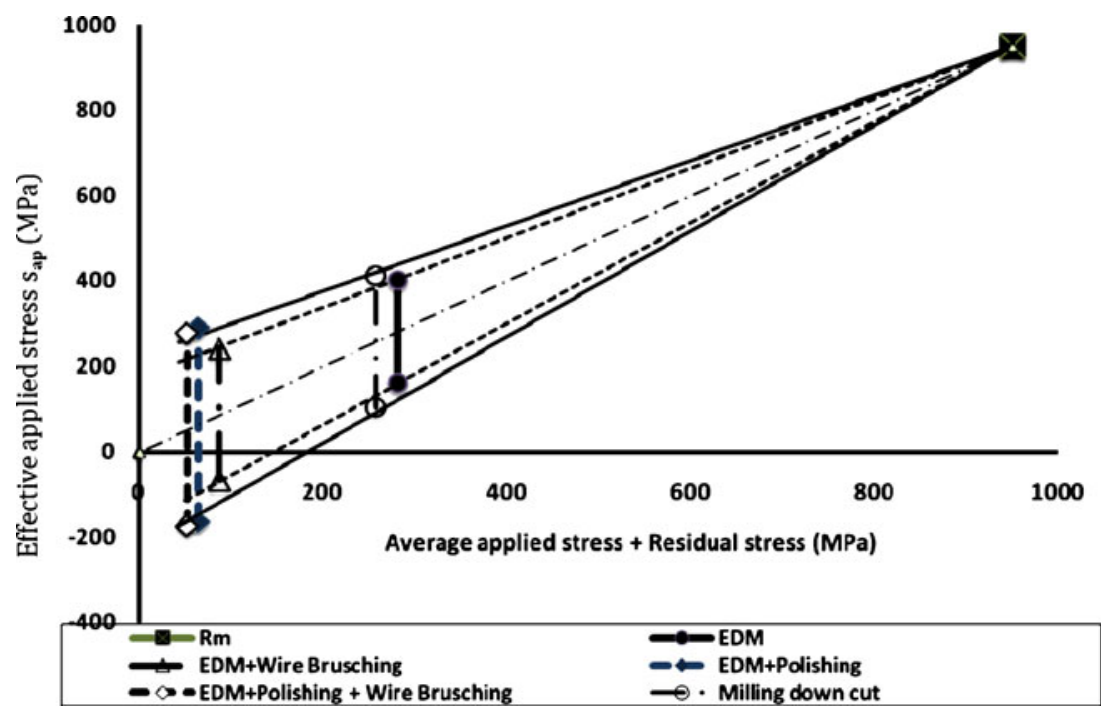

\subsection{Fatigue strength improvements}

Based on the findings of this work, it can be stated that the main advantage from the application of the wire brushing process is its ability to stabilise the propagation of the crack networks created by the EDM process under cyclic loading. This is realised by the generation of compressive residual stresses field around these cracks. It is shown that a stabilised compressive residual stress level around $-100 \mathrm{MPa}$ is enough to stabilise the propagation of the crack networks and to restore to the endurance limit its initial value measured for the milled state.

The application of the polishing process is found to remove simultaneously the white layer and the crack networks crated by EDM. In addition, this finishing process generates compressive residual stresses that stabilise at around $-130 \mathrm{MPa}$ after $2 \times 10^{6}$ fatigue cycles. These contribute to improve the endurance limit comparatively with EDM. Indeed the results of this investigation show that an increasing rate of $+70 \%$ of the endurance limit could be realised by polishing EDM surfaces. This rate could be slightly increased by the application of the wire brushing process to polished surfaces $(+75 \%)$. In order to quantify the damage induced by the crack networks generated by the EDM process, regarding to the endurance limit, the Goodman-Smith diagram was plotted (Fig. 13). This diagram uses the rupture strength $\left(R_{\mathrm{m}}\right)$ of the EN X160CrMoV12 tool steel and the different values of the endurance limits at $2 \times 10^{6}$ cycles evaluated for the different surface preparation modes (EDM: $\sigma_{\mathrm{D}}=185 \mathrm{MPa}$; wire brushing: $\sigma_{\mathrm{D}}=247 \mathrm{MPa}$; polishing after EDM: $\sigma_{\mathrm{D}}=$ $315 \mathrm{MPa}$; brushing after polishing and EDM: $\sigma_{\mathrm{D}}=$ $325 \mathrm{MPa}$; milled state: $\sigma_{\mathrm{D}}=250 \mathrm{MPa}$ [5]).

In this diagram, two plots are shown (Fig. 13). Continuous line plots are used to determine the endurance limit depending on the stabilised surface residual stress (after $2 \times$ $10^{6}$ cycles) for crack-free surfaces, i.e. milled surface, polished surface and polished and wire brushed surface. Dot line plots give the relationship between the stabilised surface residual stresses and the endurance limit evaluated for damaged surfaces by the crack networks. By using these plots, it is possible to quantify the effect of the damage induced by the crack networks on the endurance limit for given values of stabilised surface residual stress and average applied stress. The effect of this isotropic damage can be expressed by the variable $D$ [25]:

$D=1-\frac{\sigma_{\mathrm{D}}^{2 \times 10^{6}}}{\sigma_{\mathrm{D}}^{*} 2 \times 10^{6}}$

For a given value of average applied stress + stabilised residual stress:

$\sigma_{\mathrm{D}}^{2 \times 10^{6}}$ : is the corresponding effective applied stress determined from the Goodman-Smith diagram to a surface preparation mode characterised by surface crack networks (i.e. EDM, wire brushing after EDM; dot lines).

$\sigma_{\mathrm{D}}^{* 2 \times 10^{6}}$ : is the corresponding effective applied stress determined from the Goodman-Smith diagram to a surface preparation mode characterised by a crack-free surface (i.e. polishing, wire brushing after polishing and milling; continuous lines).

This damage effect is evaluated for the EDM surface and for brushed surface after EDM as crack networks are present for these cases only.

$D_{\mathrm{EDM}}=1-\frac{185}{276} \approx D_{\text {wire brushing after EDM }}=1-\frac{247}{368}=0.34$

The damage effect induced by the crack networks is found to be slightly dependent on the surface preparation 
mode. Therefore, it can be stated that the application of the wire brushing to EDM surfaces forces the level of stabilised residual stress to shift to higher compressive values without altering the effects of the damage induced by the crack networks. The diagram of Goodman-Smith shows clearly that the endurance limit of the EDM specimens could be restored to their value measured for the milled state by shifting the stabilised residual stress to more compressive values as a result of the application of the of wire brushing.

\section{Conclusions}

Results of this investigation have put in evidence the efficiency of the wire brushing process as a finishing technique of EDM components. The application of this process to EDM surfaces forces the state of the residual stresses to shift from tensile to compressive. This was found to stabilise the crack networks generated by the EDM process and consequently to improve significantly the endurance limits at $2 \times 10^{6}$ cycles of components initially machined by EDM. The realised improvements $(+34 \%)$ are similar to those obtained by the shot peening process. These improvement rates of the endurance limit could be increased further when crack networks were removed by polishing and by the application of the wire brushing process to polished components that were initially obtained by EDM. In this case, the realised improvements are around $70 \%$ and $75 \%$ comparatively to the EDM state for polishing and wire brushing following polishing, respectively. This was made possible because polishing eliminates completely the crack networks generated by the EDM and induces compressive residual stresses to these surfaces that are amplified by the application of the wire brushing.

\section{References}

1. Ho KH, Newman ST (2003) State of the art electrical discharge machining (EDM). Int J Mach Tools Manuf 43:1287-130

2. Yeo SH, Kurnia W, Tan PC (2008) Critical assessment and numerical comparison of electro-thermal models in EDM. J Mater Process Technol 203:241-251

3. Ghanem F, Atig KB, Salah NB, Braham C (2007) Prédiction par calcul de la rugosité totale d'une surface usinée par électroérosion. Matériaux et Techniques 94:419-428

4. Ghanem F, Braham C, Sidhom H (2003) Influence of steel type on electrical discharge machined surface integrity. J Mater Process Technol 142:163-173

5. Ghanem F, Fredj N B, Sidhom H, Braham C (2003) Influence du mode de fraisage sur l'intégrité de surface et la tenue en fatigue des pièces usinées, SF2M ,22 $2^{\text {èmes }}$ Journées de Printemps, Commission de Fatigue, CETIM Senlis, 21 and 22 May 2003

6. Hiong LS, Xiaoping L (2003) Study of the surface integrity of the machined workpiece in the EDM of tungsten carbide. J Mater Process Technol 139:315-321

7. Choi KK, Nam WJ, Lee YS (2008) Effects of heat treatment on the surface of a die steel STD11 machined by W-EDM. J Mater Process Technol 201:580-584

8. Ghanem F, Braham C, Fitzpatrick ME, Sidhom H (2002) Effect of near-surface residual stress and microstructure modification from machining on the fatigue endurance of tool steel. J Mater Eng Perform 11:631-639

9. Grosch J (1989) Einflu $\beta$ der funkenerosiven Bearbeitung auf das Randgefüge verschiedener Stähle. HTM 44:290-295

10. Tadao T, Takeo T (1987) Effect of the electro-discharge machined surface on the mechanical properties. Bull Japan Soc of Prec Engg 21( $\left.\mathrm{N}^{\circ} 1\right): 70-71$

11. Kisuke I, Katsuji T (1988) Fatigue strength of shot penned specimen formed by laser cutting and wire EDM. Bull Japan Soc of Prec Engg 22(N³):195-199

12. Walbank J (1980) Wear of spark-eroded (EDM) brass stamping dies. Metallurgia 47(1):4-6

13. Hocheng H, Lei W, Hsu HS (1997) Preliminary study of material removal in electrical-discharge machining of SiC/Al. J Mater Process Technol 63(1-3):813-818

14. Fordham JD, Pilkington R, Tangt CC (1997) The effect of different profiling techniques on the fatigue performance of metallic membranes of AISI 301 and Inconel 718. Int J Fatigue 19:487-501

15. AGIE (1987) Controlling EDM surface integrity. American Machinist and Automated Manufacturing 81-83

16. Guu YH, Hocheng H (2001) Improvement of fatigue life of electrical discharge machined AISI D2 tool steel by TiN coating. Mater Sci Eng, A 318:155-162

17. Yan BH, Lin YC, Huang FY (2002) Surface modification of Al$\mathrm{Zn}-\mathrm{Mg}$ alloy by combined electrical discharge machining with ball burnish machining. Int J Mach Tools Manuf 42:925-934

18. Wang ZL, Fang Y, Wu PN, Zhao WS, Cheng K (2002) Surface modification process by electrical discharge machining with a Ti powder green compact electrode. J Mater Process Technol 129:139-142

19. Cheng LY, Hwa BY, Song YC (2000) Machining characteristics of titanium alloy (Ti-6Al-4V) using a combination process of EDM with USM. J Mater Process Technol 104:171-177

20. Fredj NB, Nasr MB, Rhouma AB, Braham C, Sidhom H (2004) Fatigue life improvements of the AISI 304 stainless steel ground surfaces by wire brushing. J Mater Eng Perform 13:564-574

21. Novovie D, Dewes RC, Aspinwall DK, Voice W, Bowen P (2004) The effect of machined topography and integrity on fatigue life. Int J Mach Tools Manuf 44:125-134

22. Ataollah J, Ulfried R, Wilfried E (2008) The effect of machining on the surface integrity and fatigue life. Int J Fatigue 30:20502055

23. Sheng-Kuei L, Yung-Li L, Ming-Wei L (2001) Evaluation of the staircase and the accelerated test methods for fatigue limit distribution. Int J Fatigue 23:75-83

24. Peças P, Henriques E (2008) Electrical discharge machining using simple and powder-mixed dielectric: the effect of the electrode area in the surface roughness and topography. J Mater Process Technol 200:250-258

25. Lemaitre J, Chaboche J-L (1990) Mechanics of solid materials. Cambridge University Press, UK 